\title{
Assessing Financial Risk Spillover and Panic Impact of Covid-19 on European and Vietnam Stock market
}

\author{
Massoud Moslehpour ${ }^{1,2} \cdot$ Ahmad Al-Fadly $^{3} \cdot$ Syed Ehsanullah ${ }^{4} \cdot$ Kwong Wing Chong $^{5} \cdot$ Nguyen Thi My Xuyen $^{6}$. \\ Luc Phan Tan ${ }^{7}$
}

Received: 19 November 2021 / Accepted: 13 December 2021 / Published online: 6 January 2022

(c) The Author(s), under exclusive licence to Springer-Verlag GmbH Germany, part of Springer Nature 2022

\begin{abstract}
This study examined the influence of tail risks on global financial markets, which aids in better understanding of the emergence of COVID-19. This study looks at the global and Vietnamese stock markets impacted by the COVID-19 pandemic to identify systemic emergencies. Risk dependent value $(\mathrm{CoVaR})$ and Delta link VaR are two important tail-related risk indicators used in Conditional Bivariate Dynamic Correlation (DCC) (CoVaR). The empirical findings demonstrate that when COVID-19's worldwide spread widens, the volatility transmission of systemic risks across the global stock market and multiple exchanges shifts and becomes more relevant over time. At the time of COVID-19, the world industrial market was larger than the Vietnamese stock market, and the Vietnamese stock market posed a lesser danger to the global market. A closer examination of the link between the Vietnam value-at-risk $(\mathrm{VaR})$ range index sample and the world stock index indicates a significant degree of downside risk integration in key monetary systems, particularly during the COVID-19 era. Our study findings may help regulators, politicians, and portfolio risk managers in Vietnam and worldwide during the unique moment of uncertainty created by the COVID-19 epidemic.
\end{abstract}

Keywords COVID-19 $\cdot$ Vietnam and global $\cdot$ Stock $\cdot$ Markets $\cdot$ Systemic $\cdot$ Risk $\cdot$ CoVaR $\cdot \Delta$ CoVaR $\cdot$ Connectedness

\section{Introduction}

When the securities market is highly uncertain, the risk distribution widens dramatically, jeopardizing the system's overall stability. Adverse events, in particular, can

Responsible Editor: Philipp Gariguess

Nguyen Thi My Xuyen

xuyen.ntm@vlu.edu.vn

Massoud Moslehpour

writetodrm@gmail.com

Ahmad Al-Fadly

alfadly.a@gust.edu.kw

Syed Ehsanullah

syed_ehsan_ullah@oyagsb.uum.edu.my

Kwong Wing Chong

wingchong.kwong@taylors.edu.my

Luc Phan Tan

lucpt@tdmu.edu.vn

1 Department of Business Administration, Asia University, 500, Lioufeng Rd., Wufeng, Taichung 41354, Taiwan cause chain reactions and pessimistic expectations (Chesbrough, 2020), (such as the 1997-98 Asian financial crisis, the 2007-2008 global financial crisis, and the 2010-2013 European debt). The new coronavirus (formally known as COVID- 19, classified as the most severe infectious disease epidemic) is putting pressure on the stock market. COVID19 was first discovered at the end of 2019 in Wuhan, Hubei

2 Department of Management, California State University, San Bernardino 5500, University Parkway, San Bernardino, CA 92407, USA

3 Gulf University for Science \& Technology, Mubarak Al-Abdullah, Kuwait

4 Universiti Utara Malaysia, Sintok, Malaysia

5 School of Professional Studies, Taylor's College, Taylor's Lakeside Campus, No. 1 Jalan Taylor's, 47500 Subang Jaya, Selangor, Malaysia

6 Faculty of Business Administration, Van Lang University, 69/68 Dang Thuy Tram, Ward 13, Binh Thanh Dist., Ho Chi Minh City, Vietnam

7 Thu Dau Mot University, Binh Duong, Vietnam 
Province, central China (Sadiq et al., 2021a; Hale et al., 2020). A health emergency of international concern was declared on January 30, 2020. The virus has spread in all over the world since late February 2020. COVID-19 cases have been confirmed in over 12 million people around the world. By the beginning of July 2020, the budget for more than 500,000 victims has been released. The spread of COVID-19 has piqued the public's interest. In terms of the global economy's prospective, the most economic activities have been reawakened and frozen. As a result of the sudden drop, the financial market became unstable. Vietnam have experienced the most significant one-day declines in history, daily price increases indicate increased volatility (Hale et al., 2020). It is difficult to assess the economic and financial impact if the epidemic continues. Investors and portfolio managers faced unprecedented challenges because of this catastrophic event. As a result, they're forced to embark on a perilous journey to adopt new investment strategies that could boost profits while lowering risk (Mohsin et al., 2021) and (Agyekum et al., 2021).

Stock return will be hit by high volatility at the same time. COVID-19's unprecedented health crisis examines extreme parallel movements among global markets, evaluates their interdependence and infection, and impacts financial stability. It highlights the importance of making a choice. Several studies in the financial literature have looked into the financial market transmission or spillover and compared the results before and after a negative situation (Atalan, 2020; Chang et al., 2021; Crane et al., 2020; Farsalinos et al., n.d.; Lawal, 2021; Li et al., 2021; Sadiq et al., 2021b). Most of these studies use the GARCH (Multivariate Conditional Autoregressive Heterogeneous Variance) method to deal with conditional volatility and correlation. Various studies overlook the most important systemic risks in global financial markets while underestimating the potential for risk spillovers (Conlon and McGee, 2020)(Coibion et al., 2020; del Rio-Chanona et al., 2020; Id, 2021a; Prem et al., 2020; Sabat et al., 2020; Sadiq et al., 2021c; Chien et al., 2021). This has a significant impact on the stock market's stability.

The pattern created by the pandemic has led to increased risk aversion and the consequent "jumping" of liquid stocks, leading to high volatility in many risky asset classes (Sebhatu et al., 2020; Li et al., 2021; Liu et al., 2021). COVID-19 has had a fatal impact on health, but it is characterized by a global blockade of Vietnam and dark prospects in many areas (Tunio et al., 2021) and (Cavallino and De Fiore, 2020). It is also in an unprecedented dangerous economic situation.

Furthermore, according to (Lindsey et al., 2020; Xiang et al., 2021), dynamic reasoning will almost certainly play an important role at this stage of the pandemic. In response to the epidemic, the fiscal system exaggerated market panic and promoted commercial activities, resulting in sharp price fluctuations (Yarovaya et al., 2021b)(Chen et al., 2020) As a result, rational investors liquidate high-risk assets such as stocks and replace them with safe assets such as currencies and government bonds to restructure their investment portfolios (Hepburn et al., 2020). The rapid withdrawal of the investment portfolio increases the highest risk exposure. This behavior of investors will lead to market consolidation, which will lead to financial pollution of the entire system and increase the risk of financial market turmoil (Elsheikh et al., 2021; Tropea and De Rango, 2020). The interdependence of Girardi is used in the tail in this regard (Y. Zhang et al., 2020a, b). The study also used Adrian and Brunnermeier's Delta-CoVaR (CoVaR), whose conditional hazard (CoVaR) is used for "contribution" and "exposure." These indicators exceed a certain level of reliability and the sum of value at risk (VaR), which calculates the maximum damage a country can suffer in a given period of time (Morgan et al., 2020), but VaR does not recognize that the country is part of a system that may experience instability, especially during crises and constitute a new source of systemic risk (Mukanjari and Sterner, 2020). The "contribution" of CoVaR depends on the economic difficulties of individual countries as defined in the global market VaR. (Furceri et al., 2020). The "contribution" of any country's CoVaR is the difference between the CoVaR that depends on the world market of the difficult country and the CoVaR that depends on the world market of the country in a stable state (Taherzadeh, 2021).

In this study, in order to generate CoVaR and CoVaR estimates, we first use the univariate GARCH model to calculate the VaR of global and Vietnamese exchanges and each target country market. The following uses a conditional correlation (DCC) model of two dynamic variables to estimate the global pair of each country in Vietnam (Davidsson et al., 2021).

The impact of COVID-19 on financial markets has recently become the focus of various research (Baker et al., 2020; Coccia, 2020; Goodell and Huynh, 2020; Hanke et al., 2020; Kapata et al., 2020; Kraus et al., 2020; Roser et al., 2020).

There is a lack of evidence, on whether the deadly COVID-19 epidemic has produced a major link between infectious disease, and whether this has a significant influence on stock return. In two ways, we contribute to the scientific literature. It backs up prior studies by disregarding the influence of sad occurrences on global stock markets' severe parallel movement. According to recent research, market losses under elastic situations are higher than market losses in neutral conditions (i.e. Chang et al., 2021; De Vito and Gomez, 2020). As a result, examining the distribution of tail risks in global financial markets will aid in a better understanding of communication during tough market periods like the COVID-19 era. The 
14 economies most affected by COVID-191 (the United States, Spain, Italy, China, Germany, Turkey, France, the United Kingdom, Belgium, Switzerland, Netherlands, Austria, Canada, and South Korea) are included in the sample. Our findings focus on portfolio rebalancing and hedging techniques used by global portfolio managers to offset the additional systemic risks of current economic and financial developments connected to the COVID-19 pandemic. The combined results reveal a strong link between the chance of a severe stock market fall, particularly in COVID-19. This work consists of the following sections: Section 2 contains our data and descriptive analysis, whereas Section 3 describes our technique. The empirical findings are presented in Section 4. In part 5, the article contains the conclusion.

\section{Data analysis and descriptive statistics}

The Morgan Stanley Capital International (MSCI) index is used to analyze the global and Vietnamese stock markets and the stock markets of 14 other countries on daily basis. All indexes are presented in US \$ and derived using the Thomson Reuters database. The target nations for the study were the United States, Italy, Spain, Germany, China, France, the United Kingdom, Turkey, Switzerland, Belgium, the Netherlands, Canada, Austria, and South Korea. There were 1,170 observations each day throughout the sample period, which ran from January 7, 2016, to July 1, 2020. It also covers COVID-19's length in order to analyze the influence of this unpredictably long period on global dynamic risk interactions: each country's stock index. According to sources, as of February 20, 2020, major financial institutions (Bloomberg, Yahoo Finance, Wall Street Journal, Financial Times, etc.) have begun to pay serious attention to the COVID-19 threat. The first phase (COVID-19 and below) runs from January 7 , 2016 to February 19, 2020, and ends on December 31, 2019. Subperiod 2 (of COVID-19) will end on February 20, 2020. Our goal is to define the return of a stock as the difference between the number of the first unit in each price index, expressed as a percentage. Table 1 shows the collection of technical performance data.

In addition, all kurtosis scores indicate that all income series greater than 3 have longer sides and higher peaks than the normal distribution. Except for the conditions, all performance sets below the $1 \%$ threshold passed the Jarque-Bera test. Extensive Dickey-Fuller test results at the 1\% level demonstrate the smoothness of all performance series. The null hypothesis that successive rows and their squares are not autocorrelated is rejected by the Box-Pierce Q statistic (estimated to 20 lags), showing that the sample contains substantial linear and nonlinear correlations. All performance series show volatility clusters, according to the Lagrangian ARCH multiplier statistics with ten delays.

Table 1 Basic statistics (Descriptive)

\begin{tabular}{|c|c|c|c|c|c|c|c|c|c|}
\hline $\begin{array}{l}\text { Global Countries } \\
\text { and Vietnam }\end{array}$ & Avg & Std.Dev & Skew & Kurt.- 3 & JQBR & Ag.Dflr & $\mathrm{Q}(20)$ & $\mathrm{Q}^{2}(20)$ & $\mathrm{ARCH}$ \\
\hline USA & 0.038 & 0.751 & -1.415 & 14.932 & $11,242^{* *}$ & $-13.449^{* * *}$ & $306.266^{* * *}$ & $1289.470^{* *}$ & $68.781^{* *}$ \\
\hline Italy & -0.007 & 1.104 & -2.110 & 18.474 & $17,476^{* *}$ & $-13.340^{* *}$ & $335.818^{* * *}$ & $403.832^{* *}$ & $27.165^{\text {** }}$ \\
\hline Spain & -0.012 & 1.023 & -1.742 & 16.68 & $13,155^{* *}$ & $-13.724^{* * *}$ & $370.457^{* *}$ & $507.126^{* *}$ & $37.165^{* *}$ \\
\hline Germany & 0.008 & 0.931 & -1.137 & 13.889 & 9640 ** & $-13.725^{* *}$ & $412.957^{* *}$ & $1028.270^{* *}$ & $63.348^{* *}$ \\
\hline China & 0.040 & 0.877 & -0.306 & 1.244 & $93.685^{* *}$ & $-14.522^{* *}$ & $370.151^{* *}$ & $437.271^{* *}$ & $21.253^{* *}$ \\
\hline France & 0.014 & 0.927 & -1.287 & 14.706 & $10,848^{* *}$ & $-14.220^{* *}$ & $430.956^{* *}$ & $1094.170^{* *}$ & $61.321^{* *}$ \\
\hline UK & -0.014 & 0.926 & -1.311 & 20.382 & $20,551^{* *}$ & $-14.104^{* *}$ & $364.798^{* *}$ & $755.668^{* *}$ & $41.894^{* *}$ \\
\hline Turkey & -0.041 & 1.458 & -1.200 & 9.862 & $5014 * *$ & $-14.319^{* *}$ & $327.436^{* *}$ & $222.813^{* *}$ & $23.308^{* * *}$ \\
\hline Switz & 0.021 & 0.678 & -1.334 & 13.506 & $9225^{* *}$ & $-14.318^{* *}$ & $328.490^{* *}$ & $871.519^{* *}$ & $62.821^{* *}$ \\
\hline Belgium & -0.032 & 0.996 & -1.365 & 12.771 & $8300^{* *}$ & $-13.430^{* *}$ & $420.673^{* *}$ & $1060.400^{* *}$ & $75.194^{* * *}$ \\
\hline Nether & 0.034 & 0.812 & -1.295 & 11.929 & $7252^{* *}$ & $-13.945^{* *}$ & $405.591^{* * *}$ & $940.335^{* *}$ & $50.378^{* * *}$ \\
\hline Canada & 0.017 & 0.880 & -1.143 & 24.185 & $28,719^{* *}$ & $-12.516^{* *}$ & $387.156^{* *}$ & $1113.220^{* *}$ & $60.921^{* *}$ \\
\hline Austria & -0.005 & 1.155 & -0.807 & 9.532 & $4549^{* *}$ & $-14.254^{* *}$ & $461.637^{* * *}$ & $1805.170^{* *}$ & $84.333^{* *}$ \\
\hline Korea & 0.022 & 0.989 & -0.462 & 9.577 & $4505^{* *}$ & $-14.221^{* *}$ & $395.491^{* *}$ & $453.575^{* *}$ & $45.985^{\text {** }}$ \\
\hline Vietnam & 0.029 & 0.688 & -1.349 & 17.666 & $15,543^{* *}$ & $-13.214^{* *}$ & $430.821^{* *}$ & $1208.370^{* *}$ & $73.041^{* * *}$ \\
\hline
\end{tabular}

JB is the abbreviation for the Jarque-Bera regularity test. The identification of the extension of the return series Bib Enhanced Black is abbreviated to ADF. Q (20) and Q2 (20) are drilling statistics, and trailing returns and secondary returns can have up to 20 consecutive correlations. ** The $1 \%$ threshold is used to calculate statistical significance 


\section{Methodology}

Our strategy is organized in three steps. We begin by calculating the VaR of global and national stock indexes using extreme risk (VaR), and calculate the CoVaR and CoVaR of some nations based on the VaR (systemic risk exposure) of global stock markets. This enables to think about massive disasters like COVID-19. Third, it investigates the linkage system between the VaR series of 14 stock indexes and worldwide stock indexes.

\section{Step one - VaR}

Assume that the first-order AR (1) autoregressive model represents each income group in the following way: (1) It denotes a country's global market or rate of return. For potential serial correlations, consider the autoregressive rate of return. It is a constant, and the autoregressive feedback parameter is a one-time error term (T1) determined by the above-mentioned data.

$$
\begin{gathered}
r_{i t}=c_{i}+v_{i} r_{i t}-1+\varepsilon_{i t} \\
\varepsilon_{i t} \mid \Omega_{t-1} \approx N\left(0 H_{t}\right)
\end{gathered}
$$

The conditional variance from the $\operatorname{GARCH}(1,1)$ univariate model is as follows: (2) Each performance series' conditional variance is listed below. Unconditional volatility is measured by a constant. Examine ARCH's and GARCH's effects separately.

$h_{i t}=\omega_{i}+a_{i} \varepsilon_{i t-1}^{2}+\beta_{i} h_{i t-1}$

$P\left(r_{r}^{i} \leq V_{a} R_{t}^{i, q}\right)=q$

Generate the following world or national VaR using the parameter estimate of the modified $\operatorname{GARCH}(1,1)$ model:

$V_{a} R_{q, t}^{i}=\phi^{-1}(q) \sigma_{t}^{i}$

\section{The DCC-GARCH model}

To estimate the correlation of variables across time, the second step is to compute the DCC-GARCH CoVaR and CoVaR specifications (Bretscher et al., 2020). As an example, consider the following conditional variance-covariance matrix: (5)

$H_{t}=D_{t}^{\frac{1}{2}} R_{t} D_{t}^{\frac{1}{2}}$

The diagonal matrix in the univariate GARCH model is the conditional standard deviation diagonal matrix. The conditional correlation matrix is created by multiplying the following numbers together:

$R_{t}=\left[\operatorname{diag}\left(Q_{t}\right)-1 / 2\right] Q_{t}\left[\operatorname{diag}\left(Q_{t}\right)^{-1 / 2}\right]$

where q denotes the DCC-GARCH model's standardized residual conditional covariance matrix.

$Q_{T}=\left(1-\theta_{1}-\theta_{2}\right) Q^{\prime}+\theta_{1}\left(Z_{t} Z_{t-1}^{\prime}\right)+\theta_{2} Q_{t-1}$

Below is the standardized residuals unconditional covariance matrix. This parameter is a non-negative scalar coefficient whose total is smaller than 1 when considering the effect of the initial shock and (Ferreira et al., 2020). (Sharif et al., 2020), quasi-maximum likelihood estimators are used to estimate the DCC-GARCH model's parameters. This is typically correct and accounts for the non-normal multivariate distribution of financial time series in general. (D. Zhang et al., 2020a, b) and (Holter et al., 2020) CoVaR is also computed as the quantile $\mathrm{q}$ of the conditional distribution of the world market $\mathrm{g}$, depending on the national stock index I. $\mathrm{t}$ As follows is the definition of the indicator: (da Cruz Perez et al., 2020).

$P\left(r_{t}^{g} \leq \operatorname{CoVaR}_{t}^{g / i, q} / r_{t}^{i} \leq \operatorname{VaR}_{t}^{i, q}\right)=q$

Calculate the "contribution" of CoVaR or CoVaR to evaluate the global condition VaR of a specific nation, Vietnam, as it transitions from normal to problematic (median) (Ishak et al., 2020). This image depicts the United States. In collaboration with Girardi and (Tarrataca et al., 2021).

$\operatorname{CoVaR}_{t}^{g / i, q}=\phi^{-1}(q) \sigma_{t}^{g} \sqrt{1-\rho_{g i, t}^{2}}+\Phi^{-1}(q) \rho_{g i, t} \sigma_{t}^{g}$

(10) Relationships between countries that are conditional. The overall condition's standard deviation is q, and the confidence level is $5 \%$. It also computes the total CoVaR to understand how a particular marginal risk influences the overall unconditional risk. The data may be computed particular nation has difficulties (or none) (Cox et al., 2020). To lower CoVaR, apply the following formula: $(50$ percent $)=0$.

$\Delta \operatorname{CoVaR}_{t}^{g / i, q}=\operatorname{CoVaR}_{t}^{g / i, q}-\operatorname{CoVaR}_{t}^{g / b, q}$

It also employs procedures that are comparable to those used in equations. 9)-Eq. (10) Calculate CoVaR's exposure in domestic and international emergencies (12).

\section{Measures of connectedness in step three / Measures to improve connection in the third phase}

Zidouemba et al. (2020) suggested the vector autoregressive (VAR) process-based connecting technique. This approach employs extended VAR for predictive analysis of variance 
error (FEVD). The VAR classification approach is defined as follows in this study: a vector of average i.i.d.s and a vector of matrices comprising 14 risk values and calculated parameters. The covariance matrix represents the error term. If the system's covariance is stable, the coefficient matrix's moving average is utilized, and the representation is derived recursively concerning the matrix of appearance identities. (Štreimikienè and Kaftan, 2021; Wicaksono, 2020). Where can I find the error vector's variance matrix, the standard deviation error component, and the equation's vector?

The elements of the decomposition matrix are normalized as follows: (15) The connection between VaR has no measuring range. Each VaR series' system range compatibility is determined as follows. (12) The point-to-point network connection is (13), and the VaR omnidirectional connection is the direction information in the opposite direction of VaR transmission. Greetings, VaR. For each VaR series represented by TO. To find the omnidirectional connection between all VaR series and the VaR provided in FROM, apply the equations below.

$$
\begin{aligned}
& \Delta \operatorname{CoVaR}_{t}^{g / i, q}=\operatorname{CoVaR}_{t}^{g / i, q}-\mathrm{CoVaR}_{t}^{g / i, 50 \%} \\
& \Delta \operatorname{CoVaR}_{t}^{g / i, q}=\phi-1(q) \rho_{g i, t} \sigma_{t}^{g} \\
& \operatorname{VaR}_{I}=\sum_{i=1}^{p} \Phi \operatorname{VaR}_{t-i}+\varepsilon_{t} \\
& \theta_{i j}^{g}(H)=\frac{\sigma_{j j}^{-1} \sum_{h-0}^{H-1}\left(e_{i}^{!} h_{h} \sum e j\right)^{2}}{\sum_{h=0}^{H}\left(e_{i}^{!} h_{h} \sum e j\right)}
\end{aligned}
$$

\section{Empirical findings}

We give our conclusions in this section based on the steps mentioned above for estimating CoVaR and CoVaR. The results of the third stage, which involves connectivity measurements among VaR series, are also presented.

\section{VaR Analysis}

We use the univariate GARCH model to calculate the VaR for each country stock index's global stock index.

\section{CoVaR, $\triangle$ CoVaR and GARCH analysis}

When the $\mathrm{ARCH}()$ coefficients are more than 0 , they are all meaningful, Table 2 indicates that earlier shocks have had a beneficial influence on present changes. When $>0$, all GARCH() computed percentages are likewise valid.
This indicates that historical changes in conditions in each country have a beneficial influence on current situations. Furthermore, the GARCH process has come to a halt ( $\mathrm{Li}$ et al., 2020).

\section{Risk analysis of global and Vietnam}

The worldwide average unconditional VaR was 0.619 before the COVID-19 epidemic (that is, the sub-period before COVID-19) (see Table 3 below). This number climbed considerably to 2,182 when the COVID-19 epidemic began. As a result, the danger of global stock markets collapsing has increased, with volatility jumping from 0.472 to 1.714 .

Furthermore, our findings demonstrate that, to various degrees, all markets had comparable patterns are considered within the range of $(2,597-3,082)$ and $(2,597-3,082)$, respectively $(1,985-2,433)$. The incident demonstrated that global markets face negative risks in each country's stock market threats (Yao et al., 2020). According to all statistical data collected during the sample period, the stock markets of Austria, China, South Korea, and Turkey contributed the most to the CoVaR of exchanges in 14 countries.

Table 3 shows world's average CoVaR value. The sample period and the average VaR value of each of the two sub-periods are always less relevant than the market value (i.e., the average CoVaR value is more negative than the expressed VaR value). As a result, the systemic risk of stock indexes collapsing in several nations has triggered a chain reaction in the global stock market. The 14 separate stock markets are having problems, and VaR appears to be increasing. These nations contributed 0.446 percent, 0.417 percent, 324 percent, and 0.306 percent The Netherlands, Germany, Spain, and France have CoVaR ratios of 0.220 percent, 0.209 percent, 0.208 percent, and 0.207 percent, respectively, making them the world's top systemic risk suppliers. With CoVaR levels of 0.095 percent, 0.102 percent, 0.166 percent, and 0.170 percent, respectively, Vietnam, Canada, Switzerland, and Italy provided the least marginal systemic risk.

Because Cumulative Systemic Risk (CoVaR) is linked to big global financial markets, the U.S. stock market is the primary risk communication instrument during COVID19 , according to this study. These findings suggest that the adjustment of the US stock market has had a substantial influence on the VaR of global stock markets. In the worldwide market, VaRs grew by 1,821 percent, 1,579 percent, 1,551 percent, and 1,543 percent in Canada, the United Kingdom, Spain, France, and Germany, respectively. The countries that contribute the least to systemic risk are Turkey, South Korea, Switzerland, and China, with 0.996 percent, 1010 percent, 1289 percent, and 1310 percent of the global VaR market, respectively. As a result, the elasticity 
Table 2 DCC-GARCH Analysis

\begin{tabular}{|c|c|c|c|c|c|c|c|}
\hline Country & $\mathrm{Ci}$ & $\mathrm{N} i$ & $\omega i$ & $\alpha i$ & $\beta i$ & $\theta 1$ & $\theta 2$ \\
\hline SA & $80 * * *(0.018)$ & $467 * * *(0.030)$ & $12^{* * * * *}(0.0$ & 0.317 **** $(0$. & $0.683^{* * * *}(0.0370)$ & $0.067 * * * *(0.008)$ & $0.932 * * * 0.008$ \\
\hline aly & ) & 7) & 0 & 54 & 2) & $*(0.006)$ & $(0.008)$ \\
\hline Spain & 7) & 7) & 0.0 & $*(0.076)$ & 2) & $.011)$ & $.018)$ \\
\hline y & 0 & 7) & 0.0 & $.044)$ & 2) & 11) & $0.022)$ \\
\hline hi & 0 & 5) & 5) & $.035)$ & 8) & ;*** (0.026) & $0.051)$ \\
\hline France & 0 & 7) & $0.006)$ & $(0.039)$ & $.038)$ & 08) & $(0.010)$ \\
\hline UK & 0 & 9) & 005) & 9) & 4) & 07) & 0.96 \\
\hline Tur & 0.07 & $0.456 * * *$ & $0.022 * * * *(0.002)$ & $17 * * * *$ & 37) & $0.034 * * * *(0.004)$ & $0.564 * * *(0.013)$ \\
\hline Switzerland & J.0. & $0.498^{* *}(0.027)$ & $0.026 * 0.015$ & $0.167 * * * 0.054$ & $0.778^{* * *}(C$ & $0.016^{* * * *}(0.006)$ & $0.564 * * *(0.007)$ \\
\hline Belgium & & 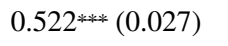 & $0.041^{* *}(0.020)$ & $45^{* * * *}(0.0744)$ & $0.727 * * *(0.092)$ & 0.054 **** $(0.012)$ & $0.543^{* * * *}(0.013)$ \\
\hline Nethe & 0.02 & 27) & $0.054 *(0.007)$ & $43^{* * *}(0$. & $0.792 * * *(0$ & $0.053^{* *}(0.015)$ & $0.543 * * *(C$ \\
\hline Canada & 0 & 5) & $*(0.013)$ & $0.167 * * * *(0.035)$ & 0.817 **** $(0.058)$ & $0.032 * * *(0.024)$ & $.051)$ \\
\hline $\mathrm{Au}$ & 0 & $=(0$. & $0.056^{* * * *}(0.007)$ & $0.210^{* * * *}(0$. & $0.752^{* * * *}(0$ & $0.014 * *(0.005)$ & $0.954 * *$ \\
\hline Korea & 0.03 & $0 * * *$ (0. & $0.016^{* * * *}(0.0$ & $0.227 * * *(0.0$ & $0.745 * * * 0$ & $0.031 * * * * 006)$ & $0.643 * * *(0.013)$ \\
\hline Vietnam & $0.045^{* * *}(0.015)$ & $0.467 * *(0.030)$ & $0.0125^{* * *}(0.003)$ & $0.317 * * *(0.017)$ & $0.683^{* * *}(0.0370)$ & $0.043(0.006)$ & $0.954 * * *(0.022)$ \\
\hline
\end{tabular}

In parenthesis, SEs with high calculation coefficients are displayed. *** Indicates statistical significance at the $1 \%$ significance level; ** indicates statistical significance at the 5\% significance level. Enter a ten percent significance criterion for statistical significance

Table 3 Vietnam and Global stock market analysis

\begin{tabular}{|c|c|c|c|c|c|c|c|}
\hline & & CoVaR & & & $\Delta \mathrm{CoVaR}$ & & \\
\hline & & $\begin{array}{l}\text { Before COVID- } \\
19\end{array}$ & $\begin{array}{l}\text { During COVID- } \\
19\end{array}$ & Whole sample & $\begin{array}{l}\text { Before COVID- } \\
19\end{array}$ & $\begin{array}{l}\text { During COVID- } \\
19\end{array}$ & Wholesample \\
\hline Vietnam/USA & MeanSD & -0.5000 .443 & -2.5971 .985 & -0.6710 .910 & -0.0840 .207 & -2.1301 .690 & -0.0950 .798 \\
\hline Vietnam /Italy & Mean SD & -0.6730 .524 & -3.0722 .051 & -0.8681 .075 & -0.0600 .087 & -1.4121 .109 & -0.1700 .493 \\
\hline Vietnam /Spain & Mean SD & -0.6960 .550 & -3.0802 .419 & -0.8901 .085 & -0.0890 .132 & -1.5511 .300 & -0.2080 .559 \\
\hline $\begin{array}{l}\text { Vietnam /Ger- } \\
\text { many }\end{array}$ & Mean SD & -0.7000 .565 & -3.0822 .422 & $-0.894-1.093$ & -0.0920 .133 & -1.5241 .245 & -0.2090 .543 \\
\hline Vietnam /China & Mean SD & -0.8520 .655 & -3.0412 .413 & -1.0301 .107 & -0.3370 .290 & -1.3101 .227 & -0.4170 .520 \\
\hline Vietnam /France & Mean SD & -0.6970 .553 & -3.0812 .423 & -0.8911 .088 & -0.0880 .121 & -1.5431 .223 & -0.2070 .541 \\
\hline Vietnam /UK & Mean SD & -0.6820 .556 & -3.0812 .419 & -0.8771 .091 & -0.0730 .131 & -1.5791 .282 & -0.1950 .564 \\
\hline Vietnam /Turkey & Mean SD & -0.8080 .636 & -2.9212 .383 & -0.9801 .080 & -0.2450 .240 & -0.9961 .010 & -0.3060 .422 \\
\hline $\begin{array}{l}\text { Vietnam /Switzer- } \\
\text { land }\end{array}$ & Mean SD & -0.6780 .547 & -3.0312 .433 & -0.8691 .082 & -0.0660 .114 & -1.2891 .218 & -0.1660 .494 \\
\hline $\begin{array}{l}\text { Vietnam /Bel- } \\
\text { gium }\end{array}$ & Mean SD & -0.6890 .550 & -3.0663 .074 & -0.8831 .084 & -0.0780 .110 & -1.3861 .121 & -0.1850 .490 \\
\hline $\begin{array}{l}\text { Vietnam /Neth- } \\
\text { erland }\end{array}$ & Mean SD & -0.7130 .572 & -3.0742 .422 & -0.9051 .092 & -0.1070 .138 & -1.4891 .295 & -0.2200 .544 \\
\hline Vietnam /Canada & Mean SD & -0.5520 .481 & -3.0192 .380 & -0.7521 .062 & -0.0500 .148 & -1.8211 .420 & -0.1020 .666 \\
\hline Vietnam /Austria & Mean SD & -0.8560 .656 & -3.0402 .373 & -1.0341 .100 & -0.3590 .328 & -1.4171 .336 & -0.4460 .572 \\
\hline Vietnam /Korea & Mean SD & $\begin{array}{l}-0.8210 .640 \\
\text { Global VaR }\end{array}$ & -2.9332 .374 & -0.9931 .080 & -0.2620 .240 & -1.0100 .978 & -0.3240 .415 \\
\hline Vietnam & Mean SD & $\begin{array}{l}\text { Pre-COVID-19 } \\
-0.6190 .472\end{array}$ & & $\begin{array}{l}\text { During COVID-19 } \\
-2.1821 .714\end{array}$ & & $\begin{array}{l}\text { Full sample } \\
-0.7460 .791\end{array}$ & \\
\hline
\end{tabular}

In parenthesis, SEs with high calculation coefficients are displayed. *** Indicates statistical significance at the $1 \%$ significance level; ** indicates statistical significance at the 5\% significance level. Enter a ten percent significance criterion for statistical significance 
of such markets' market circumstances may extend to other areas of the world.

During the research period, Fig. 1 depicts the general trend of VaR and CoVaR in each nation (2016-2020). The values of Universal $\mathrm{VaR}$ and $\mathrm{CoVaR}$ change over time on various scales in response to comparable patterns, as illustrated in the figure. Before the occurrence of COVID19 , none of the VaR or CoVaR values had changed significantly. These figures, on the other hand, have altered dramatically during COVID-19. Table 3's technical data supports this conclusion even more.

\section{The world and Vietnam face systemic risks}

Table 4 contains descriptive statistics of the average values of VaR, CoVaR, and $\Delta \mathrm{CoVaR}$ for all In the sub-period before COVID-19 (1.875), Turkey had the highest level of value at risk (absolute value), while the United States had the lowest risk (0.759). So, in the sample, Turkey is the country with the highest risk, and the United States is the safest country.

According to the CoVaR statistics in Table 4, severe total losses will be transferred to the national stock market as a result of global market benefits. Seconds before a pandemic All stock markets have risen rapidly as a result of severe losses. This figure gives no indication of the future economic and financial climate. Global stock markets will have a significant negative influence on local stock markets throughout the COVID-19 era, damaging investors' stock values. Furthermore, based on our experience and estimations, Belgium,
Austria, the United Kingdom, and Canada have CoVaR values of 4,446, 4,348, and 4,168, respectively. The most exposed markets for CoVaR are France, Italy, Germany, and Spain, with a price of 3,841,3,749,3,714,3680. China, Switzerland, Turkey, and Vietnam, on the other hand, are lowrisk markets, with a CoVaR price of 2215,2668,2834,2947. The average and standard deviation of a single daily CoVaR value is shown in the final three columns of Table 4.

The 5 percent VaR of global stock markets has been realized in average by 0.792 percent, 0.742 percent, 0.655 percent, and 0.536 percent. CoVaR values in Spain, Belgium, the United Kingdom, Germany, France, and the worldwide market are 0.309 percent, 0.288 percent, 0.286 percent. With the lowest marginal risk, the United States, Canada, Switzerland, and CoVaR had values of 0.104 percent, 0.111 percent, and 0.164 percent, respectively. The study found that the marginal systemic risk of global stock markets in specific economies is higher than the risk of the Vietnamese stock market. It can be compared to the amount of money spent on systemic risk (Table 4).

In the COVID-19 sub-period (see the last three columns of Table 4), the relevant results of the indicate that the US stock market is the primary beneficiary. Risky market. For example, the global market increased the US VaR by $2.516 \%$. These data suggest that the North American and British stock markets were less susceptible to the severe side effects of global stock market systemic risks during the COVID-19 sub-period.

Throughout the sample period, Fig. 2 depicts the VaR and CoVaR series derived in various nations from global
Fig. $1 \Delta$ CoVaR/Global and Vietnam

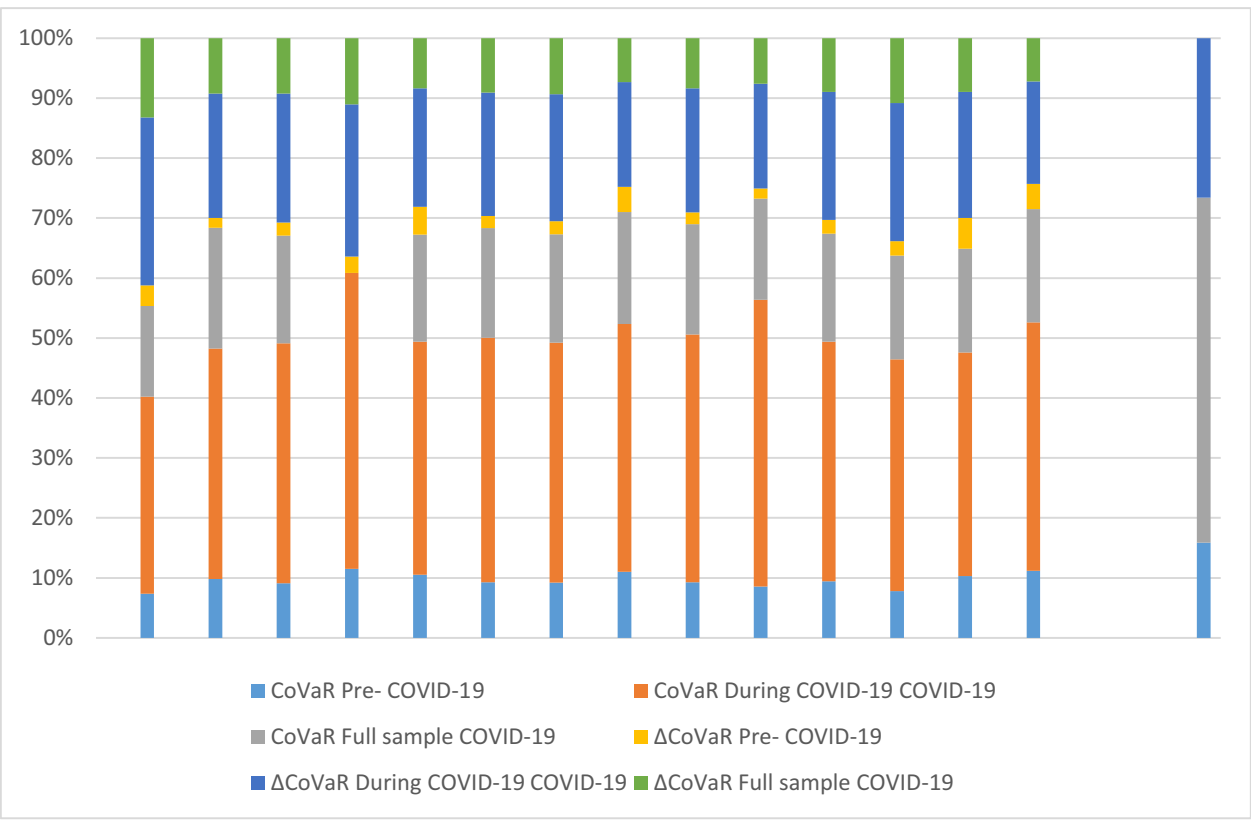




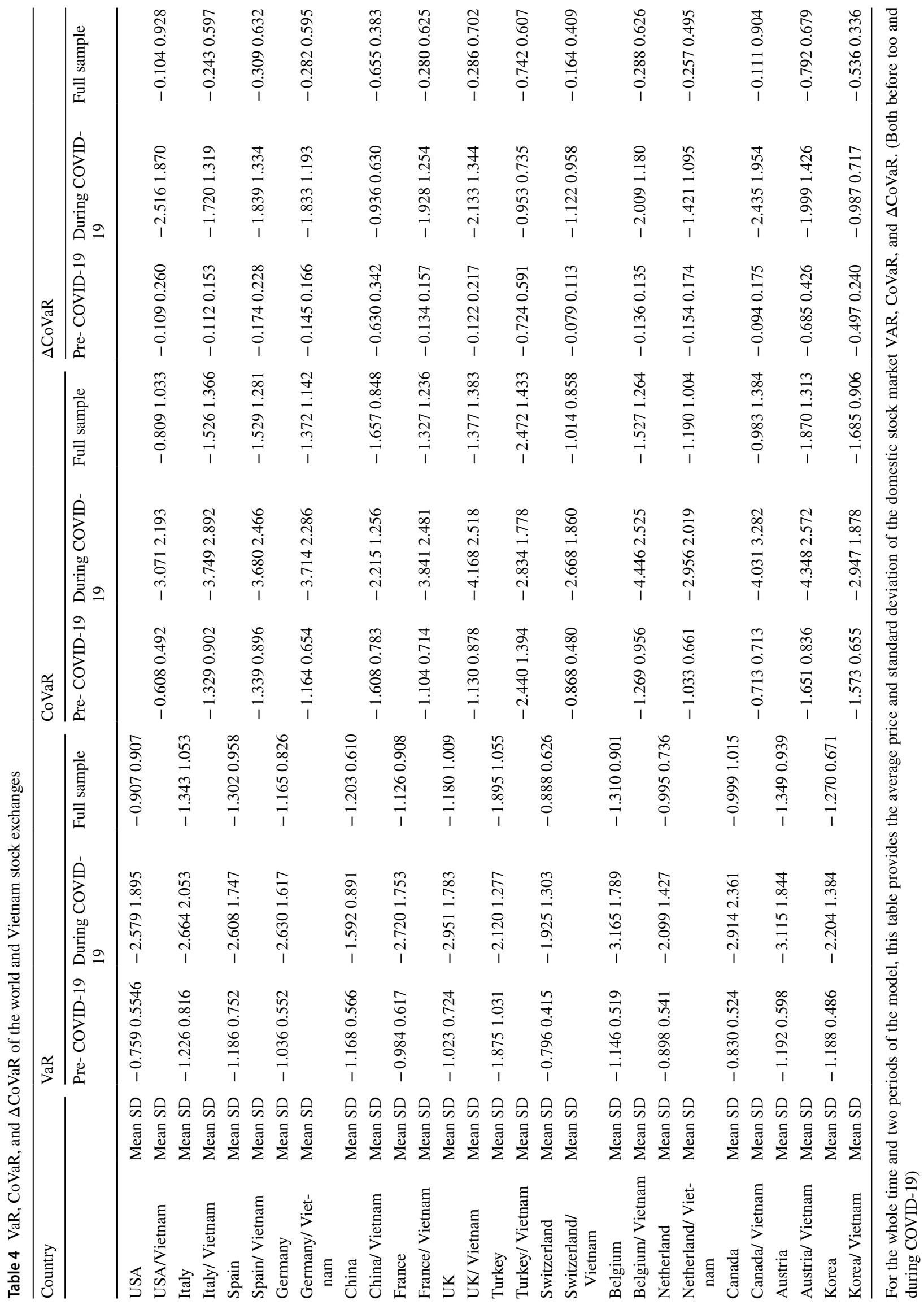


stock markets. At the start of COVID-19, however, all VaRs and CoVaRs had aberrant severity. Table 4 shows the data, which support this conclusion.

\section{Analysis of VaR connectivity measurements}

The correlation system between the VaR series of 14 stock indexes and global stock indexes is discussed in this section. This suggests that there are dangers on the downside. Let's have a look at the VaR series correlation matrix first in Table 5. The pairs United Kingdom-Switzerland, United Kingdom-Netherlands, United Kingdom-Nether except for China and Turkey, Vietnam's VaR is closely linked to the VaR of all nations.

\section{Static analysis}

First, let's look into static testing. (Brands and Gavin, 2020) proposed using VaR series to create a generic VAR connection network with a 10 -step delay and lead time. The VAR model is used to generate the decomposition matrix, and the lag and prediction time are advanced ten steps, as shown in Table 6. This high number denotes the global stock market system's high-risk integration. In particular, Turkey, China, and South Korea have minor contributions to the VaR system's risk, with values of 21.20 percent, 40.44 percent, and 45.04 percent, respectively. With a score of 179.79 percent, the worldwide index's VaR system risk is the greatest however, the major beneficiary of the net risk is (percentage).

\section{Time-varying analysis / Changes over time analysis}

The time variations of the downside risk spillover of 14 stock indexes and global stock indexes shows that the dynamic integration of the VaR series trading system based on a 200-day trading window is shown in Fig. 3. There are various values for the global spillover index. The steep drop in the first half of 2017, and a further drop to 59 percent in February 2018, was owing to trade tensions between the United States and China and the United Kingdom's concern about the EU's prospects.

After that, it stabilized in the range of about $70 \%$. In particular, risk connectivity has steadily increased since February 2020, reaching a peak of approximately $93 \%$ at the end of March 2020. 5 The outbreak of COVID-19 is the cause of the significant increase in the global leak rate within the VaR system. The latter caused severe foreclosures, leading to global economic recession and financial market turmoil (Estrada et al., 2020). This is consistent with previous studies, which show that the risk of recurrence rates for all indicators has increased. The 2007-2008 global financial crisis, etc.(Dupor and Guerrero, 2017; Dutta, 2018; Gurara and Ncube, 2013; Yarovaya et al., 2021a).

Figure 4 depicts the VaR system's net downside risk findings, which comprise 14 stock indexes and worldwide stock indexes. Based on the produced patterns, three distinct groups may be identified. Pure VaR receivers from the United States, Italy, Spain, Germany, the United Kingdom, group (except from late February to early February). The deadline is July 2020. (It's sub-period 19 in this case.) Countries that are net emitters of value-at-risk outflows, such

Fig. $2 \Delta$ CoVaR/Country






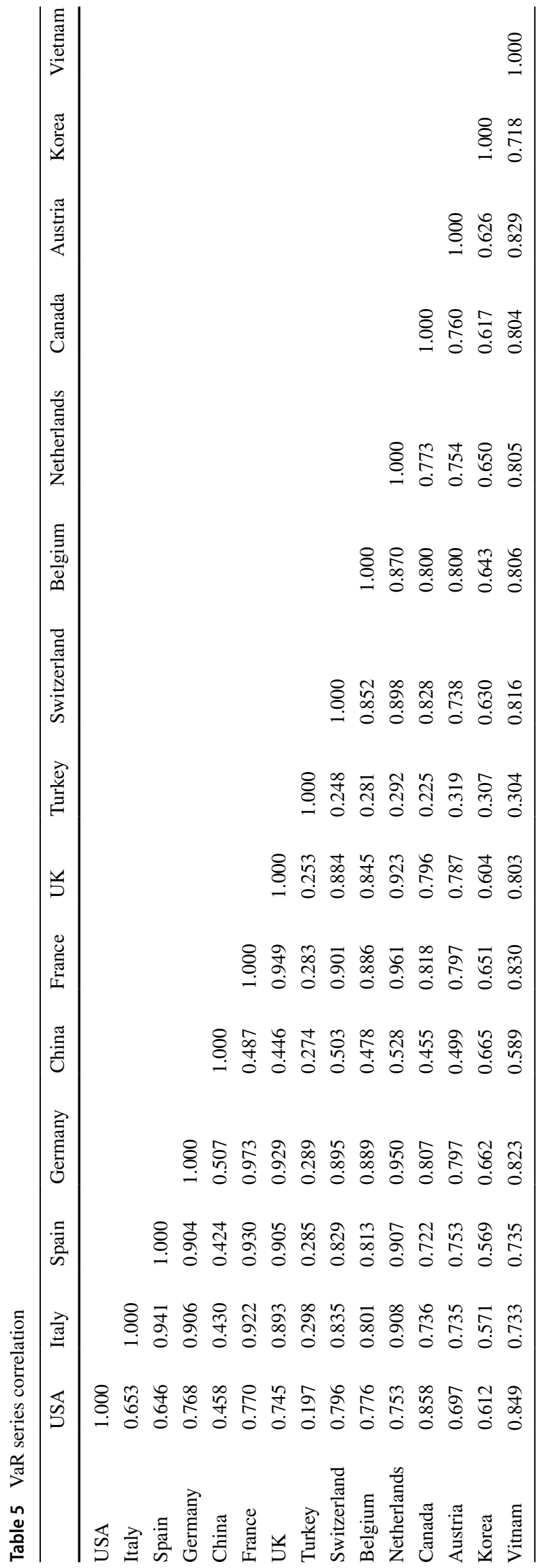

as the globe. The latter two, on the other hand, apply to COVID-19 pandemic net beneficiaries. The securities markets in the third category (France and South Korea) may be the net beneficiaries of the VaR pandemic or the VaR pandemic's net issuers. Net transmitters at other times and net receivers at different times make up the remaining sample periods. The predicted period of 5 days and the window of days will remain unchanged.

\section{Robustness tests}

The robustness test of the paper results shows that the model analyses were conducted repeatedly with dependent and independent variables. The VaR, CoVaR, and $\triangle \mathrm{CoVaR}$ averages Throughout the whole sample period as well as the two sub-periods, all of the countries that were picked across countries demonstrated a continuous upward trend around the pandemic's beginning. All samples of study applied the model tests. When the Table 7 rows and columns data is verified, it can be observed that the model tests results support our results of the study.

\section{Conclusions}

The substantial impact of systemic risk between Vietnam and global stock indexes in 14 nations badly impacted by the COVID-19 pandemic which is examined in this study. To develop the two greatest risk certainty metrics, CoVaR and CoVaR, we first utilize bivariate and multivariate DCCGARCH models. According to empirical findings, the transmission of systemic risks between global stock markets and individual exchanges surged during the COVID-19 epidemic. The North American stock market and established European markets have communicated and displayed a generally high market index risk during this pressure stage, which is primarily lower than the Vietnamese stock market.

This is similar to the overflow method used by contemporary guitarists. Overall, the findings suggest that the inventory system is in jeopardy, particularly during the COVID19 epidemic. This is in line with prior research conducted under stressful conditions such as strong economic depression episodes. This episode demonstrates that systemic risk is transferred in both directions between people and the global stock market. This enables foreign investment and portfolio managers to efficiently assess, monitor, and manage portfolio risk using the findings of this study. Second, the substantial reliance on domestic and global stock markets, particularly on global problems like COVID-19, must be taken into account when calculating systemic risk. Ignoring the component of systemic risk may lead to an underestimation of the amount of diversification tolerance as well as the influence of systemic risk on risk management. 


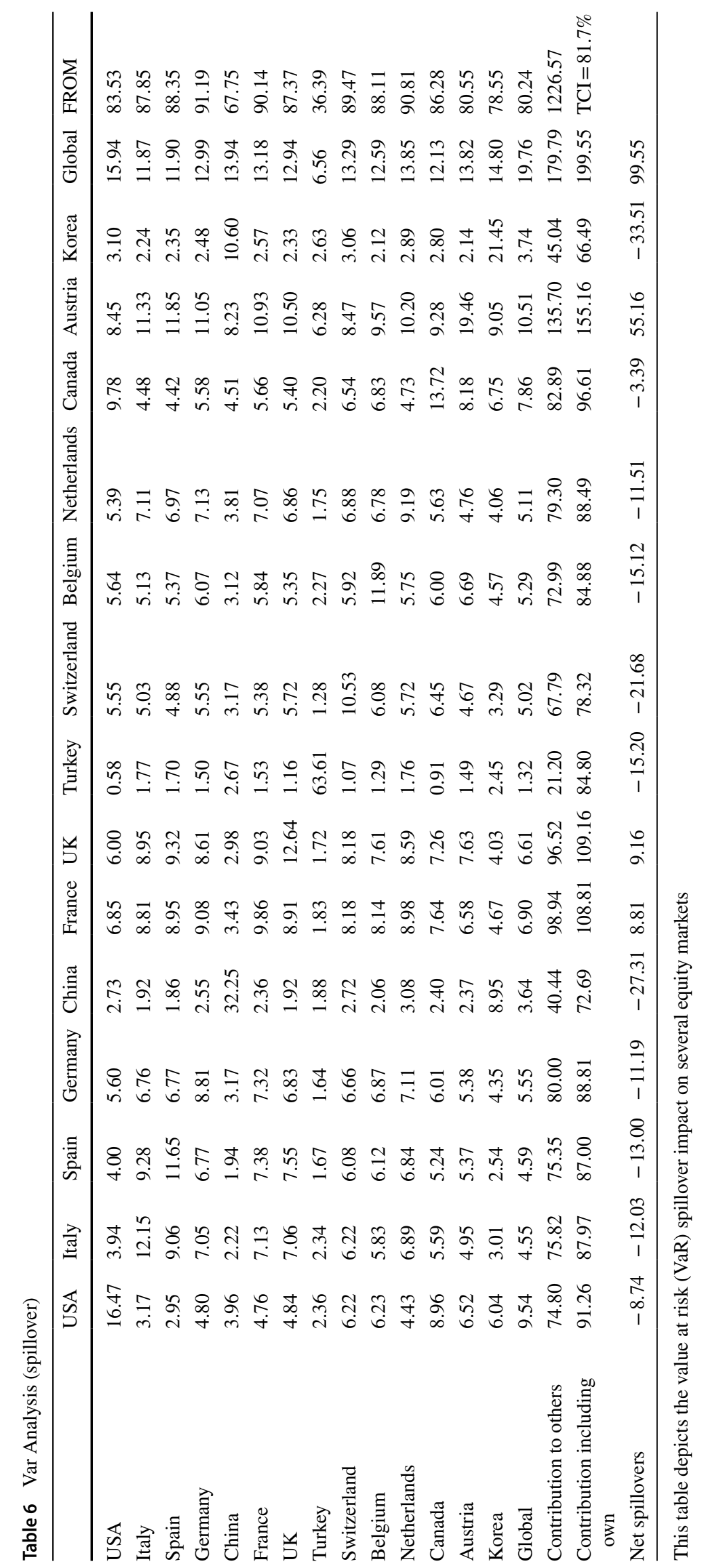


Fig. 3 Dynamic interconnection of VaR intervals in the market system



Fig. 4 All spillover model results

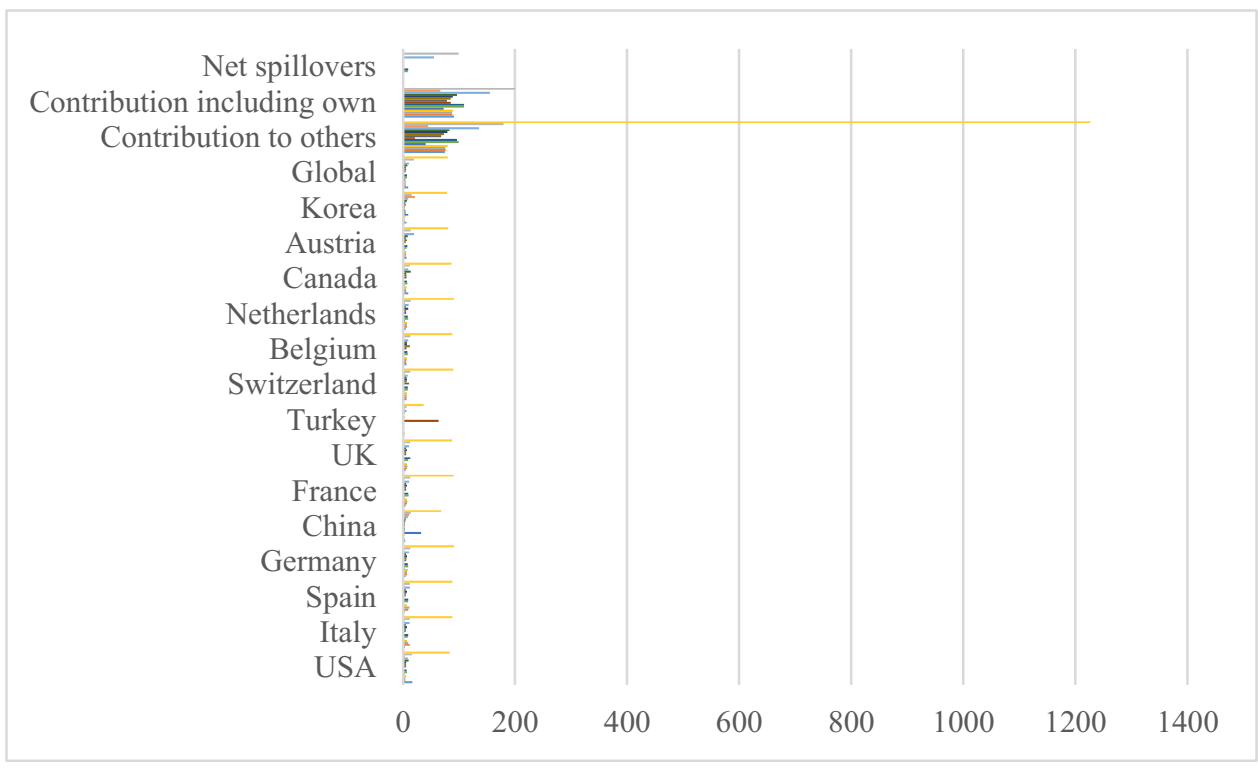

The United States has the world's largest stock market, and it may be considered a significant stock market if it has received or has received the greatest marginal risk in the global market during COVID-19. This indicates the need to diversify the capital portfolio while it is under stress. Third, COVID-19 was first listed in China, but as the pandemic spreads throughout the world.

As a result, any developments in China pertaining to the likelihood of a second COVID-19 wave should be closely observed. This is especially significant for North American and European investors. Global regulators and policymakers must evaluate the substantial interdependencies across financial markets, as well as probable changes during stressful moments, when assessing, quantifying, or categorizing systemic financial risks. Our connection metrics are relevant to building financial stability solutions with a low-risk appetite. Given the scope of the COVID-19 epidemic, systemic risks will skyrocket, as will global financial market resistance to difficulties. As a result, taking proactive steps to mitigate systemic risks is critical. Because different economic systems have different degrees of effect on systemic risks in the global market, the findings of our study can be utilized as a guide. As a result, sensible steps must be taken to reduce the excessive risk of global stock markets while maintaining the stability of local stock markets, particularly in the case of the COVID-19 outbreak's second wave. Further study may look at the systemic risk spillovers induced by COVID-19 in the global and domestic stock markets at the sectoral level as well. 


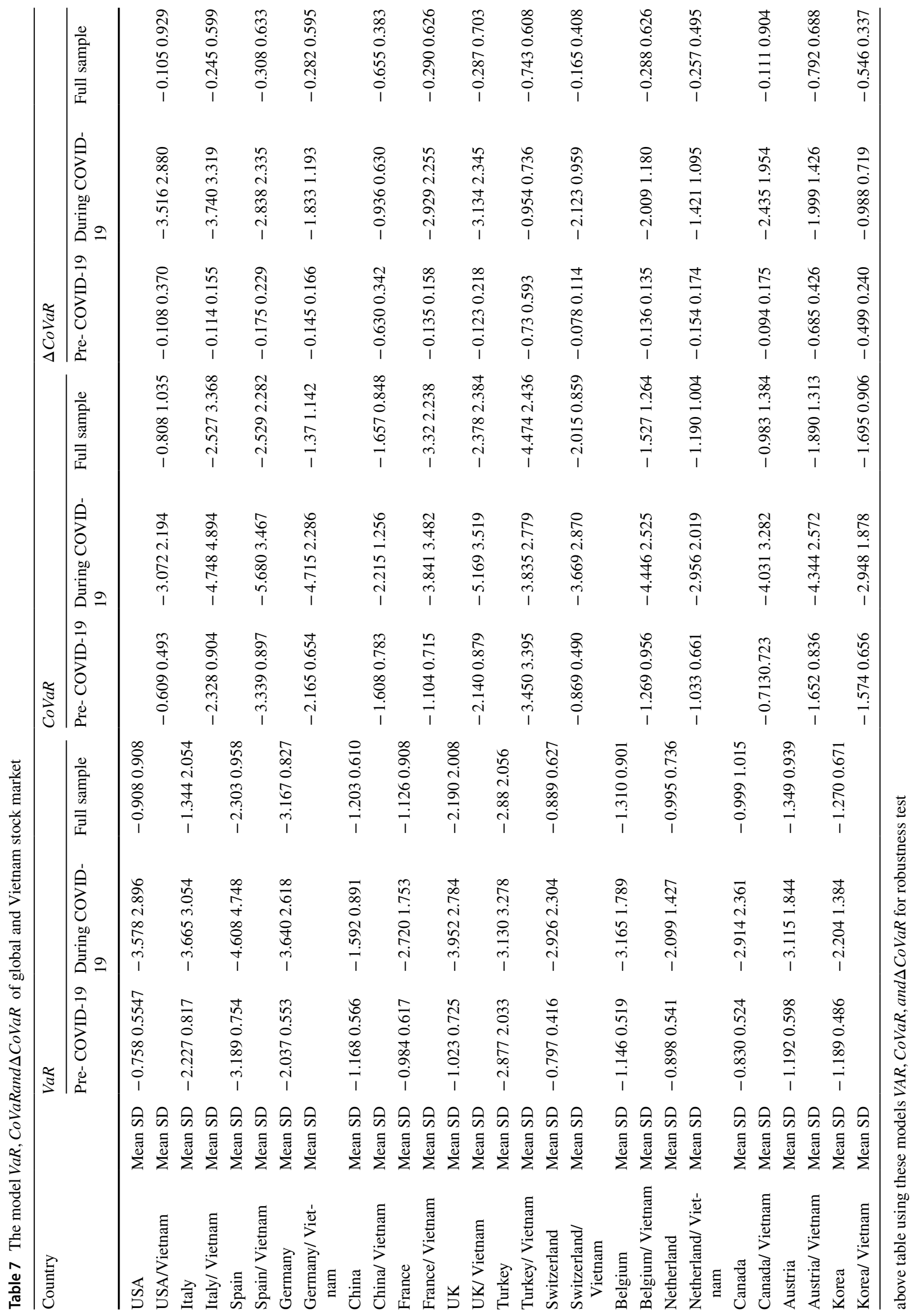


Author Contribution Massoud Moslehpour: Writing-original draft. Ahmad Al-Fadly: Writing-review \& editing. Syed Ehsan Ullah: Conceptualization Kwong Wing Chong: Methodology. Nguyen Thi My Xuyen: Data curation \& Supervision. Luc Phan Tan: Editing \& visualization.

Funding This paper is partly funded by Faculty of Business Administration, Van Lang University, Ho Chi Minh City, Vietnam.

Data Availability The data that support the findings of this study are attached.

\section{Declarations}

Ethical Approval and Consent to Participate It is declared that the authors have no known competing financial interests or personal relationships that seem to affect the work reported in this article. We declare that we have no human participants, human data, or human tissues.

Consent for Publication Not Applicable.

Conflict of interest It is declared that there is no conflict of interest.

\section{References}

Agyekum EB, Amjad F, Mohsin M, Ansah MNS 2021 A bird's eye view of Ghana's renewable energy sector environment: A MultiCriteria Decision-Making approach. Util Policy. https://doi.org/ 10.1016/j.jup.2021.101219

Atalan A (2020) Is the lockdown important to prevent the COVID-19 pandemic? Effects on psychology, environment and economyperspective. Ann Med Surg 56:38-42

S Baker N Bloom S Davis S Terry 2020 COVID-Induced Economic Uncertainty J ChemInf Model https://doi.org/10.3386/w26983

Brands H, Gavin FJ (2020) COVID-19 and world order: The future of conflict, competition, and cooperation. Johns Hopkins University Press

Cavallino P, De Fiore F 2020 Central banks' response to Covid-19 in advanced economies. BIS Bull. 21.

Chang S, Pierson E, Koh PW, Gerardin J, Redbird B, Grusky D, Leskovec J (2021) Mobility network models of COVID-19 explain inequities and inform reopening. Nature 589:82-87

Chen S, Igan D, Pierri N, Presbitero A 2020 The economic impact of Covid-19 in Europe and the US.

Chesbrough H (2020) To recover faster from Covid-19, open up: Managerial implications from an open innovation perspective. Ind Mark Manag 88:410-413

F Chien M Sadiq HW Kamran MA Nawaz MS Hussain M Raza 2021 Co-movement of energy prices and stock market return: environmental wavelet nexus of COVID-19 pandemic from the USA, Europe, and China Environ SciPollut Res https://doi.org/10.1007/ s11356-021-12938-2

Coccia M 2020 An index to quantify environmental risk of exposure to future epidemics of the COVID-19 and similar viral agents: Theory and practice. Environ Res. 191, 110155.
Coibion O, Gorodnichenko Y, Weber M 2020 The cost of the covid-19 crisis: Lockdowns, macroeconomic expectations, and consumer spending. Natl Bur Econ Res

Conlon T, McGee R 2020 Safe haven or risky hazard? Bitcoin during the Covid-19 bear market. Financ Res Lett. https://doi.org/ 10.1016/j.frl.2020.101607

Corbet S, Larkin C, Lucey B 2020 The contagion effects of the COVID19 pandemic: Evidence from gold and cryptocurrencies. Financ Res Lett. https://doi.org/10.1016/j.frl.2020.101554

Crane LD, Decker RA, Flaaen A, Hamins-Puertolas A, Kurz C 2020 Business Exit During the COVID-19 Pandemic: Non-Traditional Measures in Historical Context.

da Cruz Perez DE, Passos KKM, Machado RA, Martelli-Junior H, Bonan PRF, 2020 Continuing education in oral cancer during coronavirus disease 2019 (covid-19) outbreak. Oral Oncol.

Davidsson P, Recker J, von Briel F 2021 COVID-19 as External Enabler of entrepreneurship practice and research. BRQ Bus Res Q. 23409444211008904.

De Vito A, Gomez J-P 2020 Estimating the COVID-19 cash crunch: Global evidence and policy. J. Account. Public Policy 39, 106741.

del Rio-Chanona RM, Mealy P, Pichler A, Lafond F, Farmer JD (2020) Supply and demand shocks in the COVID-19 pandemic: An industry and occupation perspective. Oxford Rev Econ Policy 36:S94-S137

Dupor B, Guerrero R (2017) Local and aggregate fiscal policy multipliers. J Monet Econ 92:16-30. https://doi.org/10.1016/j.jmone co.2017.07.007

Dutta A (2018) A note on the implied volatility spillovers between gold and silver markets. Resour Policy 55:192-195

Elsheikh AH, Saba AI, Abd Elaziz M, Lu S, Shanmugan S, Muthuramalingam T, Kumar R, Mosleh AO, Essa FA, Shehabeldeen TA (2021) Deep learning-based forecasting model for COVID-19 outbreak in Saudi Arabia. Process Saf Environ Prot 149:223-233

Estrada MAR, Koutronas E, Lee M 2020 Stagpression: The economic and financial impact of Covid-19 Pandemic. SSRN Electron. J. January.

Farsalinos K, Poulas K, Kouretas D, Vantarakis A, Leotsinidis M, Kouvelas D, Docea AO, Kostoff R, Gerotziafas GT, Antoniou MN (n.d) Improved strategies to counter the COVID-19 pandemic: lockdowns vs. primary and community healthcare, Toxicol. Rep. $820211-9$.

Ferreira CM, Sá MJ, Martins JG, Serpa S (2020) The COVID-19 contagion-pandemic dyad: a view from social sciences. Societies 10:77

Furceri D, Loungani P, Ostry JD, Pizzuto P (2020) Will Covid-19 affect inequality? Evid Past Pandemics Covid Econ 12:138-157

Goodell JW, Huynh TLD 2020 Did Congress trade ahead? Considering the reaction of US industries to COVID-19, in: Finance Research Letters. https://doi.org/10.1016/j.frl.2020.101578

Gurara DZ, Ncube M 2013 Global economic spillovers to Africa: A GVAR approach. African Development Bank Abidjan.

Hale T, Petherick A, Phillips T, Webster S (2020) Variation in government responses to COVID-19. Blavatnik Sch Gov Work Pap 31:2011-2020

Hanke M, Kosolapova M, Weissensteiner A 2020 COVID-19 and market expectations: Evidence from option-implied densities. Econ. Lett. 195, 109441.

Hepburn C, O'Callaghan B, Stern N, Stiglitz J, Zenghelis D (2020) Will COVID-19 fiscal recovery packages accelerate or retard progress on climate change? Oxford Rev Econ Policy 36:S359-S381. https://doi. org/10.1093/oxrep/graa015

Holter JC, Pischke SE, de Boer E, Lind A, Jenum S, Holten AR, Tonby K, Barratt-Due A, Sokolova M, Schjalm C (2020) Systemic complement activation is associated with respiratory failure in COVID-19 hospitalized patients. Proc Natl Acad Sci 117:25018-25025

Id $\mathrm{S} 2021$ a covid 8.

Id S 2021b Covid 7 Baloch. 
Ishak S, Omar ARC, Osman LH (2020) Sympathy and Benevolence of Business Entities: Evidence during the COVID-19 Pandemic Outbreak. Int J Acad Res Bus Soc Sci 10:102-113

Kapata N, Ihekweazu C, Ntoumi F, Raji T, Chanda-Kapata P, Mwaba P, Mukonka V, Bates M, Tembo J, Corman V (2020) Is Africa prepared for tackling the COVID-19 (SARS-CoV-2) epidemic. Lessons from past outbreaks, ongoing pan-African public health efforts, and implications for the future. Int J Infect Dis 93:233-236

Kraus S, Clauss T, Breier M, Gast J, Zardini A, Tiberius V (2020) The economics of COVID-19: initial empirical evidence on how family firms in five European countries cope with the corona crisis. Int J Entrep Behav Res 26(5):1067-1092. https://doi.org/10.1108/ IJEBR-04-2020-0214

Lawal Y (2021) Africa's low COVID-19 mortality rate: A paradox? Int J Infect Dis 102:118-122

Li L, Strahan PE, Zhang S (2020) Banks as lenders of first resort: Evidence from the COVID-19 crisis. Rev Corp Financ Stud 9:472-500

W Li F Chien H Kamran W Aldeehani T M Sadiq M Nguyen VC Taghizadeh-Hesary F 2021 The nexus between COVID-19 fear and stock market volatility Econ Res-EkonomskaIstraživanja https://doi.org/ 10.1080/1331677X.2021.1914125

Z Liu YM Tang KY Chau F Chien W Iqbal M Sadiq 2021 Incorporating strategic petroleum reserve and welfare losses: A way forward for the policy development of crude oil resources in South Asia Resour Policy https://doi.org/10.1016/j.resourpol.2021.102309

Lindsey P, Allan J, Brehony P, Dickman A, Robson A, Begg C, Bhammar H, Blanken L, Breuer T, Fitzgerald K (2020) Conserving Africa's wildlife and wildlands through the COVID-19 crisis and beyond. Nat Ecol Evol 4:1300-1310

Mohsin M, Ullah H, Iqbal N, Iqbal W, Taghizadeh-Hesary F (2021) How external debt led to economic growth in South Asia: A policy perspective analysis from quantile regression. Econ Anal Policy 72:423-437. https://doi.org/10.1016/J.EAP.2021.09.012

Morgan T, Anokhin S, Ofstein L, Friske W $(2020)<$ ? covid19? > SME response to major exogenous shocks: The bright and dark sides of business model pivoting. Int Small Bus J 38:369-379

Prem K, Liu Y, Russell TW, Kucharski AJ, Eggo RM, Davies N, Flasche S, Clifford S, Pearson CAB, Munday JD (2020) The effect of control strategies to reduce social mixing on outcomes of the COVID-19 epidemic in Wuhan, China: a modelling study. Lancet Public Heal 5:e261-e270

Roser M, Ritchie H, Ortiz-Ospina E, Hasell J 2020 Coronavirus pandemic (COVID-19). Our world data.

Othman Z, Nordin MFF, Sadiq M (2020) GST fraud prevention to ensure business sustainability: A Malaysian case study. J Asian Bus Econ Stud 27(3):245-265

M Sadiq CC Hsu Y Zhang FS Chien 2021 a COVID-19 fear and volatility index movements: empirical insights from ASEAN stock markets Environ Sci Pollut Res. https://doi.org/10.1007/s11356-021-15064-1

M Sadiq S Nonthapot K Mohamad OC Ehsanullah S Iqbal N 2021b Does Green Finance Matters for Sustainable Entrepreneurship and Environmental Corporate Social Responsibility during Covid-19? China Financ Rev Int. https://doi.org/10.1108/CFRI-02-2021-0038

M Sadiq S Alajlani MS Hussain R Ahmad F Bashir S Chupradit 2021c Impact of credit, liquidity, and systematic risk on financial structure: comparative investigation from sustainable production Environ Sci Pollut Res https://doi.org/10.1007/s11356-021-17276-x

Sabat I, Neuman-Böhme S, Varghese NE, Barros PP, Brouwer W, van Exel J, Schreyögg J, Stargardt T 2020 United but divided: Policy responses and people's perceptions in the EU during the COVID-19 outbreak. Health Policy (New. York). 124, 909-918.

Sebhatu A, Wennberg K, Arora-Jonsson S, Lindberg SI (2020) Explaining the homogeneous diffusion of COVID-19 nonpharmaceutical interventions across heterogeneous countries. Proc Natl Acad Sci 117:21201-21208

A Sharif C Aloui L Yarovaya 2020 COVID-19 pandemic, oil prices, stock market, geopolitical risk and policy uncertainty nexus in the US economy: Fresh evidence from the wavelet-based approach Int Rev Financ Anal https://doi.org/10.1016/j.irfa.2020.101496

Štreimikienè D, Kaftan V (2021) Green finance and the economic threats during COVID-19 pandemic. Terra Econ 19:105-113

Taherzadeh O 2021 Promise of a green economic recovery post-Covid: Trojan horse or turning point? Glob Sustain https://doi.org/10.1017/ sus. 2020.33

Tarrataca L, Dias CM, Haddad DB, De Arruda EF (2021) Flattening the curves: on-off lock-down strategies for COVID-19 with an application to Brazil. J Math Ind 11:1-18

Tropea M, De Rango F (2020) COVID-19 in Italy: current state, impact and ICT-based solutions. IET Smart Cities 2:74-81

Tunio RA, Jamali RH, Mirani AA, Das G, Laghari MA, Xiao J (2021) The relationship between corporate social responsibility disclosures and financial performance: a mediating role of employee productivity. Environ Sci Pollut Res 28:10661-10677. https://doi.org/10.1007/ s11356-020-11247-4

Wicaksono RMTA 2020. Review and Analysis of Current Responses to Covid-19 in Brazil and India: Period of January to July 2020. Int. J. Soc. Sci. Relig. 81-112.

H Xiang P Ch MA Nawaz S ChupraditA Fatima M Sadiq 2021 Integration and economic viability of fueling the future with green hydrogen: An integration of its determinants from renewable economics Int J Hydrogen Energy https://doi.org/10.1016/j.ijhydene.2021.09. 067

Yao, H., Chen, J.-H., Xu, Y.-F., 2020. Rethinking online mental health services in China during the COVID-19 epidemic. Asian J Psychiatr $50,102015$.

Yarovaya L, Elsayed AH, Hammoudeh S 2021a Determinants of spillovers between Islamic and conventional financial markets: Exploring the safe haven assets during the COVID-19 pandemic Financ Res Lett 101979.

Yarovaya L, Mirza N, Abaidi J, Hasnaoui A 2021b Human Capital efficiency and equity funds' performance during the COVID-19 pandemic. Int. Rev. Econ. Financ. https://doi.org/10.1016/j.iref.2020. 09.017

Zhang D, Hu M, Ji Q 2020 Financial markets under the global pandemic of COVID-19. Financ Res Lett https://doi.org/10.1016/j.frl.2020. 101528

Zhang Y, Diao X, Chen KZ, Robinson S, Fan S 2020 Impact of COVID19 on China's macroeconomy and agri-food system-an economywide multiplier model analysis. China Agric Econ Rev

Zidouemba PR, Kinda SR, Ouedraogo IM (2020) Could COVID19 worsen food insecurity in Burkina Faso? Eur J Dev Res 32:1379-1401

Publisher's Note Springer Nature remains neutral with regard to jurisdictional claims in published maps and institutional affiliations. 